\title{
VI
}

\section{A COVID-19 REAFIRMANDO A INVISIBILIDADE DOS USUÁRIOS DE ÁLCOOL, CRACK E OUTRAS DROGAS NO TERRITÓRIO*}

Juliana Desiderio Lobo Prudencio

\section{Introdução}

O presente capítulo busca apresentar reflexões acerca da atenção aos usuários de álcool, crack e outras drogas no contexto da pandemia por coronavírus. Diante disso, se faz relevante a compreensão de quem são os usuários de drogas, em especial, em um período no qual se acirram as desigualdades sociais e as questões de saúde mental são colocadas na tônica do cuidado.

Os usuários de drogas aqui estudados são aqueles que dependem do Sistema Único de Saúde (SUS) para ter o seu cuidado em rede realizado, sobretudo os que fazem do CAPS AD seu espaço de atenção em saúde. Tais sujeitos representam uma parcela da sociedade que, no contexto da pandemia, aumentar os riscos sociais e de saúde devido a sua condição de vulnerabilidade social. Diante disso, falamos de um sujeito com classe social, cor e gênero específico, aspectos que, atrelados às inúmeras expressões da desigualdade social, vivenciadas por esses sujeitos em seu cotidiano, não permitem que muitos desses possam realizar o isolamento e distanciamento sociais.

A pandemia aprofunda a invisibilidade dos usuários de álcool, crack e outras drogas, pois auxilia no aumento da desigualdade social, tornando profundamente relevante a compreensão de quem são estes sujeitos e quais as suas reais necessidades no contexto da COVID-19, na tentativa de pensar uma atenção em saúde que possa atender as demandas deste público.

*DOI- 10.29388/978-65-86678-44-4-0-f.161-182 
Para isso, o recurso metodológico da revisão de literatura, a análise documental e o acompanhamento das publicações da mídia e redes sociais sobre a pandemia revelam que a construção do cuidado a estes sujeitos, no contexto da pandemia, precisa convocar os trabaIhadores da política de saúde mental, álcool e outras drogas a revisitar os principais marcos teóricos e legais que auxiliaram na edificação de um cuidado com base na estratégia de Redução de Danos (RD) no território. Tal estratégia precisa considerar, ainda, a sensibilidade do contexto atual, a necessidade da reconstrução de serviços, práticas e ações para a não contaminação pelo Coronavírus e o cuidado em saúde.

Todavia, é sabido que o atual contexto da política de saúde mental atualiza suas práticas balizadas em modelos antigos que reforçam a internação, a moralização do uso de drogas e a abstinência total como cuidado. Utiliza-se, ainda, das comunidades terapêuticas (CT) como espaço de atenção em saúde e abrigamento em tempo de COVID-19. O não olhar sobre os usuários de drogas como sujeito de direitos auxilia em práticas que reforçam as ações aqui citadas e silencia esses sujeitos nas políticas sociais.

\section{A pandemia de COVID-19 e os mais afetados}

Desde dezembro de 2019 estamos acompanhando países e estados sofrendo pela contaminação pelo coronavírus, cada um lançando mão de cuidados em saúde, higienização pessoal, de casas, ruas, serviços, alimentos etc. Novos protocolos de atenção à saúde são apresentados como referência importante e um pânico mundial diante da contaminação severa está posto. O vírus causa complicações no trato respiratório e não há referências de medicalização, tratamento, cuidado ou cura. Logo, a produção de cuidado e tratamento está sendo desenvolvido no momento presente.

Os primeiros casos do novo coronavírus foram registrados pela Organização Mundial da Saúde (OMS) em dezembro de 2019 em Wuhan, na China, provocando, inicialmente, o alerta sobre uma nova e avassaladora pneumonia. Com o passar dos dias, pessoas viraram números de mortos e esses números não deixam de crescer de forma 
assustadora, a contaminação se espalha pela China, Tailândia, Itália e toma conta de grande parte do globo terrestre.

A COVID-19 chega ao Brasil em fevereiro com dois casos suspeitos, sem evidências expressivas para mudanças importantes no que se refere a aplicação de novos protocolos para o trato da doença. Apenas em 12 de março de 2020, com 60 casos confirmados de COVID-19 no Brasil, as medidas começam a ser pensadas e em 16 de março é decretado o isolamento social e a quarentena em alguns estados, conforme orientação do Ministério da Saúde (MS), acatada pelos governadores e prefeitos. A cidade do Rio de Janeiro inicia a quarentena nesta data como medida para a redução de contágio, já considerado comunitário, e tal medida era importante para a tentativa de não sobrecarregar o Sistema único de Saúde (SUS) que já estava no CTI antes da pandemia.

A declaração de existência de uma pandemia de COVID-19 vem junto do reconhecimento de falhas por parte do OMS que não tratou do tema de forma mais urgente e cautelosa desde os primeiros casos. Atrelado a isso, tem-se no Brasil o posicionamento simplista do presidente da república sobre o contágio e precauções necessárias para conter a contaminação, o que não ajuda para a contenção do vírus e sim polariza a discussão sobre a importância do isolamento social. Em 20 de março iniciou-se de forma mais incisiva o fechamento de espaços que causariam maior proliferação do vírus e uma convocação nacional para o isolamento social.

Aos poucos percebe-se que era necessário uma melhor adesão, apesar da postura do presidente, a esta iniciativa e alguns estados apenas permitiram a abertura de serviços imprescindíveis para a manutenção do cuidado e sobrevivência na pandemia, os chamados "serviços essenciais", tais como: hospitais, atenção básica de saúde, farmácias, transportes públicos, transportes privados (taxi e carros de aplicativos) e supermercados.

A lógica do fechamento total se apresentou como medida mais drástica diante de um cenário de horror pelo crescente número de contágio e morte. Fechar tudo, parar tudo foi e é a medida mais eficaz de cuidado para a redução do número de mortes, diminuição da rapidez na contaminação pelo vírus e a não sobrecarga do SUS. O isolamento social e as iniciativas de cuidado de si e dos outros apre- 
sentados pela OMS são o caminho necessário para evitar que o vírus circule e que mais pessoas adoeçam, morram ou que se sobrecarregue o SUS. No entanto, quem pode atender ao fechamento total? Quem pode assumir um isolamento social? Qual a parte da população brasileira que possui o privilégio de deixar seu trabalho para cuidar de si e de sua família sem que sua renda e sobrevivência seja ameaçada? Quais são os sujeitos que sofreram/sofrerão pela COVID19 com a sobrecarga do SUS, as consequências econômicas do isolamento social e o desemprego? Qual a classe, o gênero e a cor desses sujeitos?

É o/a trabalhador/a que faz entregas e aluga a bicicleta; é a/o motorista do aplicativo de transporte que aluga o carro numa concessionária ou que adquire o seu próprio numa interminável prisão de parcelas ou "correntes" bancárias; é a/o profissional que "vende" seus serviços à prefeitura como "trabalhador/a autônomo/a" (MARRO, 2020).

A classe trabalhadora brasileira mais pobre não está na economia formal e seus direitos trabalhistas estão sendo violados, "outra tendência que gostaríamos de destacar é a da expansão do trabaIho em domicílio, permitida pela desconcentração do processo produtivo, pela expansão de pequenas e médias unidades produtivas" (ANTUNES, 2005, p. 80). Com o isolamento social, a grande massa da classe trabalhadora é convocada a passar fome, fazendo o medo da contaminação se tornar ínfimo diante dos medos impostos pelo cotidiano da desigualdade social.

A classe trabalhadora possui ameaças diárias que tornam o coronavírus apenas mais um, pois o medo da violência urbana, doméstica, do Estado, da bala "perdida", o alto índice de desemprego, a ausência de políticas sociais dentre tantos outros já estão presentes no cotidiano desses sujeitos e de suas famílias. Isso tudo aliado a um cenário precário das condições sanitárias decorrente de uma política de urbanização e habitacional que não atende às demandas das áreas mais pobres.

Fica claro que, ao impor o isolamento social, não se pensou em medidas governamentais de urgência para a classe mais vulnerável como caminho de atenção às suas necessidades básicas. Não se 
pensou em como manter isolada uma família numerada que mora em um quarto e sala de aluguel nas grandes periferias. Não se pensou em como alimentar essas famílias. Não se pensou como o coronavírus seria apenas mais um mal que eles atravessariam, diante de tantos problemas já existentes pela desigualdade social. As medidas iniciais se inspiraram em realidades que não consideravam a pobreza brasileira e que aprofundam nossas desigualdades sociais e mostram a ausência do trato estatal para com os mais pobres, deixando claro quem pode morrer, como parte da nossa bem orquestrada necropolítica.

Conforme aponta a pesquisa do Instituto Brasileiro de Geografia e Estatística - IBGE (2010), esses sujeitos vivem em área de risco, sem saneamento básico ou água tratada, em habitações precárias e com poucos cômodos, impedindo o isolamento social e a proteção de idosos, crianças e pessoas com comorbidades, entendidos como mais vulneráveis.

No dia 03/05, observamos a inversão do número de casos dos bairros mais ricos para os de menor renda. Neste movimento de transferência da maioria do contágio da Zona Sul e Centro para Zona Norte e Oeste demarcam o sentido centro-periferia que é a característica decisiva do fluxo de contaminação numa cidade marcadamente desigual como o Rio de Janeiro (BARBOSA; TEIXEIRA; BRAGA, 2020, p. 6).

O coronavírus mostra a necessidade de uma nova maneira de cuidado em saúde e apresenta medidas importantes de Redução de Danos (RD) sociais e à saúde para conter o avanço da contaminação pelo vírus. No entanto, as medidas sanitárias adotadas como RD desde março de 2020 no Brasil as quais tratam de: higienização das mãos, higienização de si e dos alimentos com água, sabão, água sanitária, álcool $70 \%$ ou álcool em gel, não foram pensadas de forma a atender os sujeitos mais vulneráveis.

A COVID-19 foi inicialmente apresentada como uma doença democrática. Permanece a interpretação médica de que os índices de infecção, bem como de situações graves e óbitos, tendem a caracterizar grupos com maiores riscos de contágio e desenvolvimento da doença. Contudo, outros públicos vêm sendo significativamente contaminados. Se ninguém está imune ao contágio e a possíveis complica- 
ções da COVID-19, as condições de seu enfrentamento são desiguais para diversos segmentos populacionais (SILVA; RUIZ, 2020, p. 2).

Os usuários do SUS foram os menos pensados quando se instauraram medidas de isolamento e higienização. As ações atendem a uma classe que possui privilégios, assalariamento e condições de saneamento que possibilitam tais medidas e, mesmo assim, não as sustentaram. Os mais vulneráveis, mais uma vez, ficaram à mercê da solidariedade da sociedade civil e do descaso do poder público.

A solidariedade avançou com a iniciativa da sociedade civil de doar alimentos e material de higiene, em especial nas favelas brasileiras e ação governamental se deu através do auxílio emergencial, garantindo $\mathrm{R} \$ 600,00$ como "renda" para trabalhadores informais. Cabe destacar que o valor do auxílio emergencial está muito aquém de responder as necessidades básicas da população. No entanto, é um avanço diante do valor de $\mathrm{R} \$ 200,00$ ofertado pelo presidente. No que tange o acesso ao auxílio emergencial trouxe mal-estar, caos e aglomerações nas agências da Caixa Econômica Federal. Com isso, observa-se uma desproteção social dos mais pobres registrados através do aprofundamento da desigualdade social e o elevado índice de negligência estatal. Nas palavras de Harvey (2020, p. 15), "os vírus mudam o tempo todo. Mas as circunstâncias nas quais uma mutação se torna uma ameaça à vida dependem das ações humanas".

Diante disso, nota-se que a população vulnerável e parte desta fica ainda mais vulnerável na exposição ao vírus e parte destes são o público da Política de Saúde Mental, Álcool e Outras Drogas em acompanhamento e cuidado no SUS. Os usuários de álcool, crack e outras drogas, no contexto da pandemia, precisam lidar com a possível contaminação pelo coronavírus e com as questões que tangenciam os usos de drogas, atrelado a sua invisibilidade na política social, pois ainda são vistos de forma preconceituosa, estigmatizada e sofrem a toda a desigualdade social exposta até aqui.

Para algumas pessoas atribuímos a condição de usuário de drogas; para outras, a de traficante. Se um ou outro, diz respeito a classe social e à raça. Há negação da relação com as drogas para ambos, mas algumas pessoas têm negado a sua própria condição de cidadania, e 
a partir daí desencadeia-se a negação de todas as suas escolhas e sua própria existência invisibilizada (FERRUGEM, 2019, p. 34).

O usuário de drogas, como cidadão invisível, apresenta em sua existência marcas profundas da desigualdade social e preconceito. Ainda é compreendido por muitos como o drogado que, devido à "vagabundagem", prefere usar drogas a trabalhar ou ainda como um sujeito incapaz de sustentar sua vida e fazer escolhas saudáveis e conscientes devido ao uso de drogas. Tais compreensões, presentes na nossa sociedade, que criminaliza e adoece o uso de drogas, sob a perspectiva da conjunção dos usos serem classificados como abusivos e prejudiciais, não levam em considerações os diversos usos consentidos.

As drogas psicodepressoras, que se caracterizam por sua ação calmante, soporífera e ansiolítica: o álcool, as drogas à base de ópio (ou opiáceos), barbitúricos, tranquilizantes (sedativos ou hipnóticos) ou solventes (éter e terebintina; 2 ) as drogas psicoestimulantes, como a cocaína e seus derivados, o crack, as anfetaminas, o ecstasy, e até mesmo a cafeína, o khat ou a nicotina; 3) as drogas psicodislépticas, que apresentam efeitos alucinógenos, como o LSD, alguns cogumelos e o haxixe; 4) por fim, certos remédios com efeitos psicotrópicos (BERGERON, 2012, p. 13).

A compreensão do usuário de drogas como dependente de uma substância reforça o seu lugar de vulnerável socialmente e diz sobre o seu não-lugar nas políticas sociais, pois a questão central passa a ser apenas a droga. Na sociedade brasileira o tema droga sempre foi tratado com o olhar da Segurança Pública sob a evocação da ação policial de forma repressiva e excludente. Logo, descarta-se historicamente a importância de um cuidado aos usuários de drogas como questão de Saúde Pública.

Diante disso, a "dependência da droga" coloca para as políticas sociais e aos trabalhadores das políticas sociais que o "drogado" possui a impossibilidade racional de deixar de usar; diante da capacidade "aditiva" de algumas drogas, o que resultaria em uma adição. Portanto, o drogado é visto/tachado? Como aquele que "perdeu as qualidades essenciais que fazem um sujeito social digno e respeitável" (BERGERON, 2012, p. 18). Desse modo, desconsidera-se sua his- 
tória, sua relação com a droga, sua vida e sobretudo sua compreensão como um sujeito de direito e capaz de legislar sobre si, portanto, passível de ser estigmatizado e criminalizado pelo uso de drogas.

A escassez de estudos sobre quem é o usuário de drogas na literatura e nos serviços de atenção a estes sujeitos exacerba a invisibilidade sobre o usuário de drogas como cidadão e o coloca em um não-lugar no cuidado e atenção à saúde. Observa-se, da pesquisa realizada no catálogo da CAPES, em agosto de 2020, com o termo "perfil dos usuários de drogas", uma indicação importante de 914 produções e com o termo "perfil do dependente químico" uma indicação de 143 produções.

Todavia apenas 1 produção em cada termo pesquisado nos permite uma compreensão sobre quem são esses sujeitos através de análises que perpassam a classe social, o gênero, a raça, a idade, a formação, a inserção no mercado de trabalho e os vínculos familiares $^{1}$, e assim exemplificam o que aqui já foi apresentado acerca da sua vulnerabilidade social. A grande maioria apresenta reflexões que reforçam o olhar sobre a droga e estudos dos efeitos das mais diversas substâncias.

A pesquisa realizada por Prudencio (2019) também revelou que parte dos trabalhadores da política de saúde mental, álcool e drogas na Baixada Fluminense do RJ não fazem do seu cotidiano profissional espaços para reflexão acerca de quem são os usuários dos Centros de Atenção Psicossocial Álcool e Drogas (CAPS AD) e quem são os usuários de drogas. A fala das entrevistadas mostra que os usuários de drogas são sujeitos que precisam de ajuda pela discriminação e rejeição familiar e societária, mas afirmam na pesquisa ser algo jamais pensado por todos os envolvidos.

A ausência da compreensão ou reflexão sobre quem são esses sujeitos que transitam pelas políticas sociais e se tornaram o públicoalvo do CAPS AD reforça a ideia de uma não observação sobre quem eles são, quais suas reais necessidades e os enfrentamentos no território. Os usuários de drogas apenas são vistos quando a mídia os colocam em voga, sobretudo quando a polícia tem o intuito de contê-

\footnotetext{
${ }^{1}$ Os poucos estudos apresentam que são homens pretos e/ou pardo, pobres, com idade média entre 27 e 34 anos, ensino médio incompleto, desempregados e com vínculos familiares rompidos.
} 
los, logo esta invisibilidade também influencia no acesso ao cuidado e na resposta as necessidades sociais, ou seja, ainda temos uma exclusão social dos usuários de drogas de ordem histórica como apontam Nicodemos e Elia (2016), Lindner e Siqueira (2016).

Essa exclusão social se agrava em tempos de pandemia, pois o isolamento social convocou o fechamento do território, o qual "expressa e é atravessado por rebatimento e transformações do tempo presente" (ABREU, 2016, p. 33). Nesse contexto, o fechamento do território, visto como medida de cuidado, coloca os usuários de drogas na esteira do afastamento dos serviços de atenção em saúde mental, aumentando as dificuldades dos trabalhadores de saúde mental acessarem os usuários e a ampliação do cerceamento do direito de ir e vir dos usuários de drogas. Com isso, o isolamento social promove o distanciamento do cuidado constante em saúde mental, seja nos CAPS AD, nos Consultórios na Rua ou na Atenção Básica de Saúde, ou seja, nos serviços de promoção de saúde. Logo, ocorre uma convocação para uma reorganização das equipes promotoras do cuidado na tentativa de que, mesmo em meio à pandemia, a atenção seja prestada e os direitos não violados.

$\mathrm{O}$ atual contexto pandêmico remonta a necessidade de uma organização dos trabalhadores das políticas sociais no que se refere a construção de instrumentos, técnicas ou o despertar para novos instrumentos que viabilizem o cuidado aos usuários de álcool, crack e outras drogas no território em isolamento social.

\section{A atenção aos usuários de álcool e outras drogas no con- texto da pandemia de COVID-19}

A atenção aos usuários de álcool, crack e outras drogas na sociedade brasileira desde os anos 1990 é marcada pela relação cotidiana entre repressão e a estratégia de Redução de Danos (RD) e com a pandemia de COVID-19 as equipes de saúde mental são chamadas a pensar alternativas de cuidado, dadas as orientações de isolamento e distanciamento social. Diante disto, cabe algumas indagações. No contexto da pandemia é aceitável um distanciamento dos usuários de drogas dos serviços de cuidado? Como os serviços de saúde presta- 
ram atenção em saúde e cuidado durante o isolamento social? Os trabalhadores da política de saúde mental estão preparados para o contexto de pandemia?

Não cabe a este capítulo dar respostas a estas perguntas e sim pensar caminhos possíveis para que as demandas relacionadas a elas sejam atendidas sem muitos danos sociais e à saúde. Tais perguntas são constantes por parte dos sujeitos que estão pensando e trabalhando na política de saúde mental no contexto da pandemia de COVID-19 e sem respostas concretas, mas na certeza de que é necessário se fundamentar nos referenciais já disponíveis para a atenção aos usuários de álcool, crack e outras drogas no território.

Cabe destacar que a construção da atenção aos usuários de drogas tem como marca a resistência dos profissionais de saúde a uma repressão imposta ao traficante e usuários de drogas. No contexto em que a agenda pública estava atenta e disposta à construção de um cuidado aos usuários de drogas, a partir da Saúde Pública, se inaugura um novo olhar sobre este sujeito pautado pelos princípios do SUS por meio da estratégia de RD. É necessário destacar que houve um momento favorável para a entrada do tema da atenção aos usuários de drogas na agenda da política pública, marcado por tensões e disputas. Isto muito marcado também pela gestão de Pedro Delgado na Coordenação Nacional de Saúde Mental no período de agosto a dezembro de 2000 que possibilitou a construção de um caminho de atenção aos usuários de drogas calcado na estratégia de RD.

A RD marca a atenção aos usuários de drogas como espaço de defesa da vida, liberdades individuais, escolhas, autonomia e direito de cidadania, na contramão da ideia da abstinência como única possibilidade de cuidado. Também apresenta a preocupação em reduzir os riscos sociais e de saúde aos quais os usuários de drogas estão expostos pelos usos de drogas. A aplicação da RD como estratégia para o cuidado desse público tem início nos anos de 1990 com a troca de seringas como caminho de redução de contágio, entre os usuários de drogas injetáveis, da Síndrome da Imunodeficiência Adquirida (AIDS). Sendo assim, podemos definir a RD como "ações que visam minimizar riscos e danos de natureza biológica, psicossocial e econômica provocados ou secundários ao uso de drogas sem necessariamente 
requerer a redução de consumo de tais substâncias" (ANDRADE, 2004, p. 87).

A partir da compreensão da RD como estratégia para o cuidado em saúde aos usuários de álcool, crack e outras drogas por parte daqueles que gestavam o Ministério da Saúde nos anos 2000, militantes, estudiosos e trabalhadores da política de saúde mental, álcool e outras drogas iniciaram-se ações no intuito de inserir esta estratégia no campo da política de saúde mental. Tais ações foram pensadas, conforme aponta Prudencio (2019), em especial para a expansão e qualificação de serviços para o território (os CAPS AD), a qualificação das equipes de trabalho em saúde mental, o mapeamento do território para compreensão dos serviços de atenção e combate a instituições e ações que violavam os Direitos Humanos.

Neste sentido, os anos 2000 marcam caminhos possíveis para a construção de um cuidado no território, permeado pela estratégia de RD, reforçados com a consolidação de marcos relevantes, os quais destaco: Portaria GM no 336 de 2002 que institui os CAPS em suas modalidades; Política do Ministério da Saúde para a Atenção Integral a Usuários de Álcool e Outras Drogas (PAIUAD), de 2003; e Portaria no 3588/2017 que institui modificações na Portaria 3088/2011 que trata da Rede de Atenção Psicossocial (RAPS).

A Portaria GM no 336/2002 inaugura os Centros de Atenção Psicossociais (CAPS) no campo do álcool e outras drogas na atenção psicossocial. A referida normatização apresenta o CAPS AD como espaço para cuidado ambulatorial diário, ordenador da rede de cuidado aos usuários de drogas no território e supervisão as equipes da atenção básica em saúde. Pontua a formação da equipe mínima para o cuidado e afirma seu papel de ação no território por meio de ações em rede que auxiliem a atenção integral aos usuários de drogas.

A PAIUAD materializa a aprovação da RD como estratégia de cuidado nas redes de atenção em saúde de cunho territorial com reconhecimento do CAPS AD como ordenador desta rede e como espaço legítimo de cuidado aos usuários de drogas. Com isso, a política apresenta um posicionamento contrário à abstinência total e reconhece o usuário de drogas como cidadão de direitos. Salienta, ainda, que o cuidado deve ser prescrito no território, próximo à família e dialogando com as políticas sociais, logo, nega os espaços que praticam 
a internação compulsória como possibilidade de cuidado e não cita as comunidades terapêuticas (CT) como serviço em saúde mental. Além disso, a PAIUAD convoca a mudança na atenção aos usuários de drogas, de forma integral, e afirma a necessidade de uma radical mudança na postura que reforça a repressão ao traficante e desconsidera o cuidado aos usuários de álcool, crack e outras drogas como questão de Saúde Pública.

A Portaria $\mathrm{n}$ 0 3588/2017, por outro lado, representa a abertura para uma sucessão de retrocessos que a política de saúde mental vem sofrendo, em especial na atenção aos usuários de álcool, crack e outras drogas, desde o Governo Lula, e reforça a inserção das CT na RAPS, a qual ganhou espaço no campo da droga desde a Portaria 3088/20112. A Portaria de 2017 se alia à ideia de uma "nova política de saúde mental", através do reconhecimento do cuidado através do retorno à lógica hospitalar e a convocação à abstinência total com o incentivo financeiro para aberturas de novos leitos hospitalares e a centralidade do cuidado de usuários de drogas nas CT (seja por incentivo financeiro, seja por novos credenciamentos).

A "nova política de saúde mental" reorganiza uma "nova" ação higienista e manicomial na política de saúde mental que se faz através da internação compulsória de usuários de álcool, crack e outras drogas como medidas de cuidado em saúde nas CT.

Com isto, a atenção aos usuários de álcool, crack e outras drogas no contexto da pandemia vem sendo pensada sob a ótica da "nova política de saúde mental" e se acirra na convocação pela lógica manicomial diante da prerrogativa do cuidado ser o isolamento social. Nossa luta nega o manicômio que representa a lógica do isolamento, porém, na pandemia, o cuidado, mesmo sob o olhar da RD, se expressa na necessidade do isolamento social de todos. No entanto, cabe pontuar a resistência de inúmeras equipes ao modelo imposto pelo Governo Federal de destruição da atenção através da convoca-

\footnotetext{
${ }^{2}$ A Portaria 3088/2001 institui a Rede de Atenção Psicossocial e representa um grande marco na compreensão da atenção aos usuários de drogas. Através dos seus pontos de atenção apresenta a atenção integral aos usuários de drogas e reforça a importância do cuidado ser feito no território, bem como passa a atender um campo que a Saúde Pública ainda não habitava. Cabe também pontuar que foi através desta portaria que as comunidades terapêuticas ganham visibilidade em quanto espaço de "cuidado" para usuários de drogas como representantes da sociedade civil recebendo verba pública.
} 
ção do manicômio pelas $\mathrm{CT}$, as quais se perfazem na construção de novas práticas de cuidado em saúde mental, práticas essas que, como aponta Prudencio (2019), negam a comunidade terapêutica como serviço da RAPS. Diante disso, a convocação ao isolamento social como medida de cuidado na pandemia não deve reforçar as CT como espaço de atenção em saúde.

As ações de cuidado aos usuários de álcool, crack e outras drogas em meio à pandemia precisam reforçar a lógica da RD como caminho único de atenção e buscar alternativas de cuidado. Para isto, ao ser declarado o estado de pandemia, o Ministério da Saúde (MS) lançou a Nota Técnica no 12/2020-CGMAD, a qual reconhece os serviços de saúde mental como serviço essencial e apresenta ações e medidas que devem ser tomadas no interior deles, nas equipes, no manejo clínico e na relação com a rede de cuidado na tentativa de contenção da contaminação pelo coronavírus e cuidado de possíveis contaminados. Além disso, orienta os encaminhamentos para os grupos de riscos e os que frequentam os serviços de saúde mental, reforçando a importância da articulação com a atenção básica em saúde como cuidadora no território e reafirmando a relevância da defesa da RAPS no cuidado da pessoa em sofrimento psíquico e dos usuários de álcool, crack e outras drogas.

Após o lançamento da Nota Técnica no 12/2020, o Conselho Nacional de Saúde (CNS) apresenta a Recomendação no 40/2020 do CNS com aspectos importantes que precisam ser prioridades na atenção em saúde mental, destacando a vulnerabilidade dos sujeitos que fazem uso dessa política, sobretudo os que se encontram em hospitais psiquiátricos e nos Hospitais de Custódia e Tratamento Psiquiátrico.

Cabendo lembrar que as $\mathrm{CT}$, não foram citadas em nenhum dos dois documentos analisados, mas, em 2017, o IPEA já indicava 1800 CT no Brasil e em junho de 2020 o Ministério da Cidadania ${ }^{3}$ abriu edital para 20 mil cadastros de CT e liberou 300 milhões em financiamento para essas instituições. Pontuando que estas instituições são consideradas representantes do "cuidado" de usuários de

${ }^{3}$ Disponível em: <https://www.gov.br/cidadania/pt-br/noticias-e-conteudos/desenvolvimento-social/noticias-desenvolvimento-social/reaberto-edital-publico-para-financiamentode-comunidades-terapeuticas.\%20Acesso\%20em:\%2017\%20ago>.. Acesso em: 17 ago. 2020. 
álcool, crack e outras drogas, mesmo que não legitimadas pela maioria dos trabalhadores e estudiosos da política de saúde mental.

Além disso, a Nota Técnica no 12/2020 e a Recomendação no 40/2020 apresentam a importância da higienização e da não aglomeração de pessoas para o cuidado diante da pandemia, porém as CT apresentam grandes riscos para a proliferação do vírus. Os Hospitais Psiquiátricos, Hospitais de Custódia e Tratamento Psiquiátrico e as comunidades terapêuticas como instituições totais de "tratamento" em saúde mental representam espaços de aglomeração, pouca higienização e baixos recursos para garantia de equipamentos de proteção individual. E não podemos esquecer que neste contexto elas são convocadas para a possibilidade de isolamento social de sujeitos em vulnerabilidade, aumentando o risco por morte por COVID-19.

Outro ponto que ganha destaque também na Nota Técnica no 12/2020 e na Recomendação no 40/2020 é que parte das equipes de saúde são convidadas a utilizarem tecnologias digitais para aproximação com usuários e familiares. Destacando que estamos vivenciando o crescimento da telemedicina como mecanismo para evitar aglomerações e idas aos serviços de saúde para evitar o contágio. No entanto, no caso dos usuários de drogas é importante algumas reflexões sobre o uso de tais tecnologias, uma vez que, como pontuado inicialmente, esses sujeitos na sua condição de vulnerabilidade social em alguns casos não possuem tecnologia (smartphone, notebook e /ou tablet), pacote de dados e renda que sustente o acesso a tecnologias, ou seja, muitos usuários dos serviços públicos de saúde não dispõem das condições materiais necessárias para o cuidado no atual contexto.

Com isso, se faz necessário, como bem aponta Barbosa et al (2020), uma reinvenção cuidadosa dos serviços de promoção à saúde, pois, para além dos cuidados diários já realizados no que se refere a higienização, a educação em saúde e a mudança na rotina dos serviços, as equipes devem ser convocadas a uma melhoria do cuidado de si, por meio do uso de equipamentos de proteção individual e possibilitando a aproximação, através de tecnologias, com os usuários dos serviços.

Isto tudo no contexto em que a "nova política de saúde mental" reduz os gastos públicos para a RAPS e reforça que o cuidado 
deve ser feito através da hospitalização e das CT. Diante disso, repensar estas ações requer compreender que a construção deste cuidado, que nos tirou suor e lágrimas, vem sofrendo grandes ameaças, em especial desde 2015 com o "Fora Dilma" e todo o retrocesso posto à política de saúde mental desde então, desmoronando assim todas as referências de atenção em saúde pensadas até então. A justificativa para o "problema" da RAPS, em meio a um descaso público com a saúde mental abriu o caminho para a aprovação da Portaria no 3588/2017, a qual de forma autoritária e arbitrária representa a condução do Governo Federal com a política de saúde mental.

A referida Portaria se constitui a partir da Resolução $\mathrm{n}$ ㅇ 32/2017 e toda a conjuntura política de descaso com o SUS que representa este ano. É considerada inovadora por propor o retorno de ações asilares e repressoras na política de saúde mental, álcool e outras drogas e reforçada como possibilidade de ampliação e fortalecimento da RAPS. Após 2017, a RAPS sofre mudanças que reafirmam o confinamento e o cerceamento da liberdade dos usuários de drogas, sobretudo com o fomento à ampliação de leitos hospitalares, tornando as CT um campo de maior atenção e financiamento.

Através da ampliação dos pontos de atenção que tratam diretamente de conteúdos como especialização da atenção e hospitais psiquiátricos. Tais conteúdos reforçam a lógica focal da especialização e setorização da atenção em saúde mental pautada no modelo hospitalocêntrico (PRUDENCIO; SENNA, 2018, p. 83).

O fomento para a ampliação das CT e sua maior financeirização torna este serviço a referência governamental do cuidado aos usuários de álcool, crack e outras drogas, destoando de toda a história construída em defesa do CAPS AD e da RAPS. No contexto da pandemia tem-se terreno fértil para dar visibilidade às CT como recurso para o isolamento social de usuários de drogas. A responsabilização imposta à sociedade civil, em um governo altamente desresponsabilizado, no momento da pandemia é gritante e isso evoca as CT como medida e até única medida de cuidado (nos municípios em que não se tem o CAPS AD). Isto se dá no cenário em que a redução da verba pública para os CAPS deixa tais serviços ainda mais sucateados e com redução das equipes. 
As tentativas de conter a contaminação pelo coronavírus utilizando o apelo ao isolamento social com o recurso às CT reforçam a exclusão dos usuários de drogas da esfera de cuidado e sua invisibilidade nas políticas sociais, uma vez que distancia a possibilidade de cuidado no território, a compreensão sobre o uso de droga e coloca este sujeito em situação de violação dos Direitos Humanos.

Cabe destacar, ainda, que historicamente as CT sofrem denúncias por atender a demandas por acolhimento compulsório. Neste contexto, a convocação das CT representa o quanto a pandemia auxilia no retorno dos manicômios e da lógica manicomial nos serviços de saúde mental, como modus operandi para o isolamento social. No entanto, a pandemia também convoca os trabalhadores de saúde mental e estudiosos da área para repensar ações de cuidado em rede com objetivo de romper com a lógica posta.

Com isto, é importante que os trabalhadores da política de saúde mental estejam atentos aos usuários de álcool, crack e outras drogas nos serviços, para que assim seja possível traçar novos caminhos de cuidado neste contexto. A construção do cuidado em saúde aos usuários de drogas precisa ter como caminho de ação a estratégia de Redução de Danos sociais e à saúde, a qual, através da defesa pela vida, preza por ações no território que auxiliem na compreensão dos usos de drogas.

\section{Considerações finais}

A atenção aos usuários de álcool, crack e outras drogas se constrói no exercício cotidiano das equipes de saúde mental e sofre influências diárias da maneira como a política e o social compreendem ou não tais ações em saúde. Diante disso, a pandemia de COVID19 traz para a política de saúde mental, álcool, crack e outras drogas um desafio enorme na construção de um cuidado em distanciamento social sob a lógica do isolamento.

Este desafio se dá, pois estamos tratamos de uma política que acontece pelo estar com os sujeitos, ou seja, uma clínica do cuidado que preza o contato físico, a troca de afeto, o protagonismo dos su- 
jeitos e o andar livre pelo território como caminhos de construção de uma terapêutica favorável, atenta, zelosa e respeitosa.

O usuário de álcool, crack e outras drogas, como sujeito invisível no território e sobretudo para as políticas sociais, encontra na política de saúde mental, álcool e outras drogas, em alguns casos, a possibilidade de vivenciar o estar no território como cidadão de direitos na construção da sua atenção em rede. Rede de atenção essa formada por diversos serviços que compõem as políticas sociais. Aquelas que não reconhecem o usuário de drogas como cidadão, mas com o suporte dos trabalhadores da saúde mental isso pode ser revertido.

Com a pandemia, estas possibilidades podem ser suspensas, dada a convocação ao isolamento social, uma vez que os usuários de drogas que dependem do SUS podem estar sem a real atenção em saúde, devido à forma que o cuidado vem sendo construído. A sua condição de vulnerabilidade social, acentuada no contexto atual de agravamento dos índices de desigualdade social, coloca o usuário de drogas na contramão do cuidado e na luta pela sobrevivência ao coronavírus. Uma luta real e diária, porém, sem medo, pois muitos desses sujeitos vivem assombrados pelas expressões da desigualdade social no Brasil durante toda a vida.

Existe na pandemia a necessidade de uma reestruturação dos serviços e das equipes para a atenção a estes sujeitos de forma cuidadosa, respeitosa e sem agravos à saúde. No entanto, é de pleno acordo que o sucateamento promovido à política de saúde mental, álcool e outras drogas desde 2015 somam com as dificuldades postas para a gestão deste cuidado em 2020. Que coloca na sociedade civil, a responsabilidade para prestar o cuidado em saúde através das CT e os Centros de Referência em Dependência Química (CEREDEQ).

$O$ debate sobre as CT revela que o modelo apresentado para a atenção aos usuários de álcool e outras drogas é avesso à estratégia de RD e ao construído pela política de saúde mental, pois observa-se a atenção calcada em um modelo religioso de trato conservador e violador de direitos, uma vez que o modelo oferecido se faz na prática religiosa forçada, rotina de trabalho, abstinência da droga e defesa da internação para a "cura terapêutica", bem como possibilitam a contaminação por COVID-19 diante do seu trato asilar. 
Já os CEREDEQ são instituídos a partir da Portaria n0437/2020 com a prerrogativa de tornar as organizações da sociedade civil Centros de Referência em Dependência Química. Estes centros trabalhariam junto às universidades no desenvolvimento de cuidado, acolhimento, reinserção social, formação profissional, estudo, desenvolvimento de serviços e pesquisa no campo da atenção aos usuários de álcool e outras drogas. Com isso, temos mais um serviço em disputa com os já existem e em pouco tempo já apresentam o trato do Governo Federal e sua avalanche de retrocessos na atenção aos usuários de drogas. Sem muitas análises, diante da recente Portaria n0437/2020, os CEREDEQ representam mais um serviço em que o Estado responsabilizará pela atenção e desconsiderará o necessário trato respeitoso dos serviços, em especial os CAPS AD que já apresentam uma história de luta e cuidado na atenção aos usuários de álcool, crack e outras drogas. Reforçando seu olhar avesso à atenção aos usuários de drogas sob a lógica da estratégia de Redução de Danos.

A maneira como o ano de 2020 marca a história da atenção aos usuários de álcool, crack e outras drogas mostra uma despreocupação com tais sujeitos e reforça a invisibilidade deles na sociedade. Uma pandemia marcada pelo aprofundamento das desigualdades sociais, da busca incessante por violar os direitos dos usuários de drogas e negligenciar o cuidado em saúde mental, através da convocação ao papel da sociedade civil através das CT e dos CEREDEQ e reforçando o descaso governamental.

\section{Referências}

ANDRADE, T. M. Redução de danos: um novo paradigma? In: ALEMEIDA, A. R. B. et al. (Org.). Drogas: tempos, lugares e olhares sobre seu consumo. Salvador: EDUFBA; CETAD/UFBA, 2004.

ABREU, M. H. E. Território, política social e serviço social. Campinas: Papel Social, 2016.

ANTUNES, R. 0 caracol e sua concha: ensaios sobre a nova morfologia do trabalho. São Paulo: Boitempo, 2005. 
BARBOSA, A. da. et al. Processo de trabalho e cuidado em saúde mental no Centro de Atenção Psicossocial da UERJ na pandemia de COVID-19. Revista HUPE, Rio de Janeiro: UERJ, 2020. Disponível em: <http://revista.hupe.uerj.br/WebRoot/pdf/711_pt.pdf>. Acesso em: 20 jul. 2020.

BARBOSA, J. L; TEIXEIRA, L.; BRAGA, A. Mapa social do corona. Rio de Janeiro: Observatório de Favelas, 2020.

BRASIL. Ministério da Saúde. Portaria no 336, de 19 de fevereiro de 2002. Estabelece as modalidades de Centros de Atenção Psicossocial. Brasília, 2002. Disponível em: <http://bvsms.saude.gov.br/bvs/saudelegis/gm/2002/prt0336_19_02_2002.html>. Acesso em: 10 nov. 2019.

- Ministério da Saúde. A Política do Ministério da Saúde para a atenção integral a usuários de álcool e outras drogas. Brasília, DF, 2003.

. Ministério da Saúde. Portaria GM/MS no 3.088, de 23 de dezembro de 2011. Institui a Rede de Atenção Psicossocial para pessoas com sofrimento ou transtorno mental e com necessidades de saúde decorrentes do uso de crack, álcool e outras drogas, no âmbito do Sistema Único Saúde. Brasília, 2011a. Disponível em: <www.saude.mg.gov.br>. Acesso em: 03 jul. 2020.

. Ministério da Saúde. Portaria no 3.588, de 21 de dezembro de 2017. Altera as Portarias de Consolidação no 3 e no 6 , de 28 de setembro de 2017, para dispor sobre a Rede de Atenção Psicossocial, e dá outras providências. Brasília, 2017. Disponível em: <http://bvsms.saude.gov.br/bvs/saudelegis/gm/2017/prt3588_22_12_2017.html>. Acesso em: 27 dez. 2019.

. Ministério da Saúde. Nota Técnica no12/2020 - CGMAD/

DAPES/ SAPS/ MS. Recomendações à Rede de Atenção Psicossocial sobre estratégias de organização no contexto da pandemia da COVID19. Brasília, 2020.

. Conselho Nacional de Saúde. Recomendação no 40/2020.

Recomenda a revisão da Nota Técnica no 12/2020 e a implementação de outras providências para garantir os direitos das pessoas com so- 
frimento e/ou transtorno mental e com necessidades decorrentes do uso de álcool e outras drogas, no contexto da pandemia pelo COVID19. Brasília, 2020. Disponível em: <http://conselho.saude.gov.br/recomendacoes-cns/1181-recomendacao-n-040-de-18-de-maio-de2020>. Acesso em: 30 jul. 2020.

BERGERON, H. Sociologia da droga. São Paulo: Ed ideias \& letras, 2012.

FERRUGEM, D. Guerra as drogas: e a manutenção da hierarquia racial. Belo Horizonte: Letramento, 2019.

HARVEY, D. Política anticapitalista em tempos de COVID-19. In: HARVEY, D. (Org). Coronavírus e a luta de classes. Terra sem Amos: Brasil, 2020.

IBGE. Censo demográfico 2010. Características gerais da população, religião e pessoas com deficiência. Rio de Janeiro: IBGE, 2010. Disponível em: <https://censo2010.ibge.gov.br/> Acesso em: 28 nov. 2019. (1 CD-ROM).

INSTITUTO DE PESQUISA ECONÔMICA APLIADA - IPEA. Nota técnica, n. 2 - Perfil das comunidades terapêuticas. 2017. Disponível em: <http://www.ipea.gov.br/ portal/images/stories/PDFs/nota_tecnica/20170418_nt21.pdf>. Acesso em: 05 ago. 2020

LINDNER, L.; SIQUEIRA, D. Redução de danos: como foi? O que é possível? O que é preciso? In: SOUZA, A. C. de; SOUZA, L. F.; SOUZA, E. C. O. de; ABRAHÃO, A. L. (Org.). Entre pedras e fissuras: a construção da atenção psicossocial de usuário de drogas no Brasil. São Paulo: Hucitec, 2016.

MARRO, K. Feminismo, pão e solidariedade de classe para os tempos que virão. Brasil de Fato. São Paulo, 18 de maio, 2020. Disponível em: <https://www.brasildefato.com.br/2020/ 05/18/artigo-feminismo-pao-e-solidariedade-de-classe-para-os-tempos-que-virao >. Acesso em: 5 jun. 2020.

PRUDENCIO, J. D. L. A construção das redes de atenção aos usuários de álcool e outras drogas na saúde mental de municípios da Baixada 
Fluminense do estado do Rio de Janeiro. 2019. 200f. Tese (Doutorado em Política Social) - Programa de Estudos Pós-Graduados em Política Social, Universidade Federal Fluminense, Niterói, 2019.

.; SENNA, M. C. M. Retrocessos na atenção a usuários de álcool e outras drogas. Argumentum, Vitória, v. 10, n. 3, p. 79-93, 2018. Disponível em: <https://periodicos.ufes.br/argumentum/article/ view/20854>. Acesso em: 25 ago. 2020.

SILVA, W. M. F. DA.; RUIZ, J. L. S. A centralidade do SUS na pandemia do coronavírus e as disputas com o projeto neoliberal. Physis: Revista de Saúde Coletiva, Rio de Janeiro, v. 30, n. 3, 2020. 